\title{
บUisuersily
}

\section{Mental Well-being Considerations in Preparation for Disaster Health Care: Learning From Deployment}

Mäkinen, T. H., Miettinen, S. M., \& Kernohan, G. (2015). Mental Well-being Considerations in Preparation for Disaster Health Care: Learning From Deployment. Prehospital Disaster Medicine, 30(4), 327-336. https://doi.org/10.1017/S1049023X1500477X

Link to publication record in Ulster University Research Portal

\section{Published in:}

Prehospital Disaster Medicine

Publication Status:

Published (in print/issue): 09/08/2015

DOI:

10.1017/S1049023X1500477X

\section{Document Version}

Author Accepted version

\section{General rights}

Copyright for the publications made accessible via Ulster University's Research Portal is retained by the author(s) and / or other copyright owners and it is a condition of accessing these publications that users recognise and abide by the legal requirements associated with these rights.

\section{Take down policy}

The Research Portal is Ulster University's institutional repository that provides access to Ulster's research outputs. Every effort has been made to ensure that content in the Research Portal does not infringe any person's rights, or applicable UK laws. If you discover content in the Research Portal that you believe breaches copyright or violates any law, please contact pure-support@ulster.ac.uk. 


\section{Prehospital and Disaster Medicine}

Date of delivery:

Journal and vol/article ref:

$$
\text { pdm } 1500477
$$

Number of pages (not including this page): ${ }^{10}$

This proof is sent to you on behalf of Cambridge University Press. Please print out the file and check the proofs carefully. Please ensure you answer all queries.

\begin{tabular}{l|ll} 
Please EMAIL your corrections within & $\mathbf{2}$ days of receipt to:
\end{tabular}

Mona Johnson

mjohnson@wadem.org, $\square \square$ pdm@wadem.org

Authors are strongly advised to read these proofs thoroughly because any errors missed may appear in the final published paper. This will be your ONLY chance to correct your proof. Editorial staff inspects only the appearance of typeset papers, and is not responsible for errors in content. Once published, either online or in print, no further changes can be made.

NOTE: If you have no corrections to make, please also email to authorise publication.

- The proof is sent to you for correction of typographical errors only. Revision of the substance of the text is not permitted, unless discussed with the editor of the journal. Only one set of corrections are permitted.

- Please answer carefully any author queries.

- Corrections which do NOT follow journal style will not be accepted.

- A new copy of a figure must be provided if correction of anything other than a typographical error introduced by the typesetter is required.

- If you have problems with the file please email sprice@cambridge.org

Please note that this pdf is for proof checking purposes only. It should not be distributed to third parties and may not represent the final published version.

Important: you must return any forms included with your proof. To order reprints or offprints of your article or a printed copy of the issue, please visit the Cambridge University Reprint Order Center online at: www.sheridan.com/cup/eoc. We cannot publish your article if you have not returned your signed copyright form

\section{Please do not reply to this email}

NOTE - for further information about Journals Production please consult our FAQs at http://journals.cambridge.org/production_faqs 


\section{QUERY FORM}

\section{PDM}

\begin{tabular}{|l|l|}
\hline Manuscript ID & \\
\hline Author & \\
\hline Editor & \\
\hline Publisher & \\
\hline
\end{tabular}

\section{Journal: Prehospital And Disaster Medicine}

Author :- The following queries have arisen during the editing of your manuscript. Please answer queries by making the requisite corrections at the appropriate positions in the text.

\begin{tabular}{|c|l|}
\hline Query No & \multicolumn{1}{|c|}{ Nature of Query } \\
\hline Q1 & $\begin{array}{l}\text { The distinction between surnames can be ambiguous, therefore to ensure accurate tagging for indexing purposes } \\
\text { online (eg for PubMed entries), please check that the highlighted surnames have been correctly identified, that all } \\
\text { names are in the correct order and spelt correctly. }\end{array}$ \\
\hline Q2 & Please set Table 3's float-anchore in sequence. \\
\hline
\end{tabular}




\section{Mental Well-being Considerations in Preparation for Disaster Health Care: Learning From Deployment}

Tytti H. Mäkinen, RN, MSc; ${ }^{1}$ Sari M. Miettinen, $\mathrm{PhD} ;{ }^{2}$ W. George Kernohan, $\mathrm{BSc}, \mathrm{PhD}^{1,3}$

1. Disaster Healthcare, University of South Wales, United Kingdom

2. Social and Health Policy, HAMK University of Applied Sciences, Finland

3. Ulster University, Newtownabbey, United Kingdom

Correspondence:

Tytti Mäkinen, RN, MSc

47 Mockridge Cres

Holt, ACT 2615, Australia

E-mail: itmakinen@gmail.com

Conflicts of interest: none

Keywords: disasters; education; mental health; personnel

Abbreviations:

DMAT: Disaster Medical Assistance Team

NGO: nongovernmental organization

Received: December 3, 2014

Revised: March 27, 2015

Accepted: April 9, 2015

doi:10.1017/S1049023X1500477X

\section{Abstract}

Introduction: The mental well-being of internationally deployed disaster-relief workers has become an issue of concern. The psychological consequences for the relief worker being exposed to trauma and threats have been well documented; however, the role of predeployment preparation in supporting mental well-being has not received due attention, despite research indicating the need for it.

Hypothesis/Problem: This case series examines the experiences of deployed volunteers of one emergency-relief organization. The aim of this research was to identify the participants' interpretations of the appropriateness of the pre-deployment preparation they had received in light of supporting their mental well-being during and after deployment.

The main research questions were: How appropriate was pre-deployment preparation in supporting mental well-being? What elements were lacking, and what else would be useful? Methods: Using a hermeneutic phenomenological approach, thematic, semi-structured interviews were conducted with six deployed volunteers of an international emergencyrelief organization. Data were analyzed using content analysis.

Results: The participants in this study regarded the pre-deployment preparation they had received, on the whole, as appropriate in supporting their mental well-being. The seven main themes identified as important and supportive of mental well-being were: (1) realistic expectations, (2) team building and support, (3) self-awareness and self-care, (4) postdeployment support, (5) practical skills and creative solutions, (6) shared values and beliefs, and (7) safety and security. Specific areas identified as lacking within these themes included communication, self-care, post-deployment support, and safety and security.

Conclusion: Themes identified as important for supporting mental well-being in this research largely were consistent with those in previous research. The generally positive experiences of the support received do not reflect results from existing research, where significant shortcomings in worker support have been expressed. However, important elements were also identified as lacking in this specific pre-deployment preparation.

Mäkinen TH, Miettinen SM, Kernohan WG. Mental well-being considerations in preparation for disaster health care: learning from deployment. Prehosp Disaster Med. 2015;30(4):1-10

\section{Introduction}

There has been a growing concern for the mental well-being of personnel deployed in disaster relief and rescue. Many disaster situations involve conflict with an ensuing threat of violence toward humanitarian workers, in addition to the "accepted" insecurities, including stress, culture shock, witnessing trauma, and fatigue, which almost seem to be an intrinsic part of the humanitarian profession. Some of the most salient stressors for international workers are issues often neglected in support systems. ${ }^{1}$ International relief workers have an increased risk of developing mental health consequences, with evidence of vicarious trauma, compassion fatigue, and posttraumatic stress disorder, as well as other mental health issues. ${ }^{2-7}$ The mental well-being of workers affects a larger sphere involving the recipients of relief and the families of the workers, as well as the workers' ability and willingness to return to future deployments. ${ }^{8}$ In addition to it being in the interests of deploying organizations to maintain and retain healthy and well-functioning staff, internationally accepted guidelines require provision of adequate support for staff at all stages of deployment. 1,9 


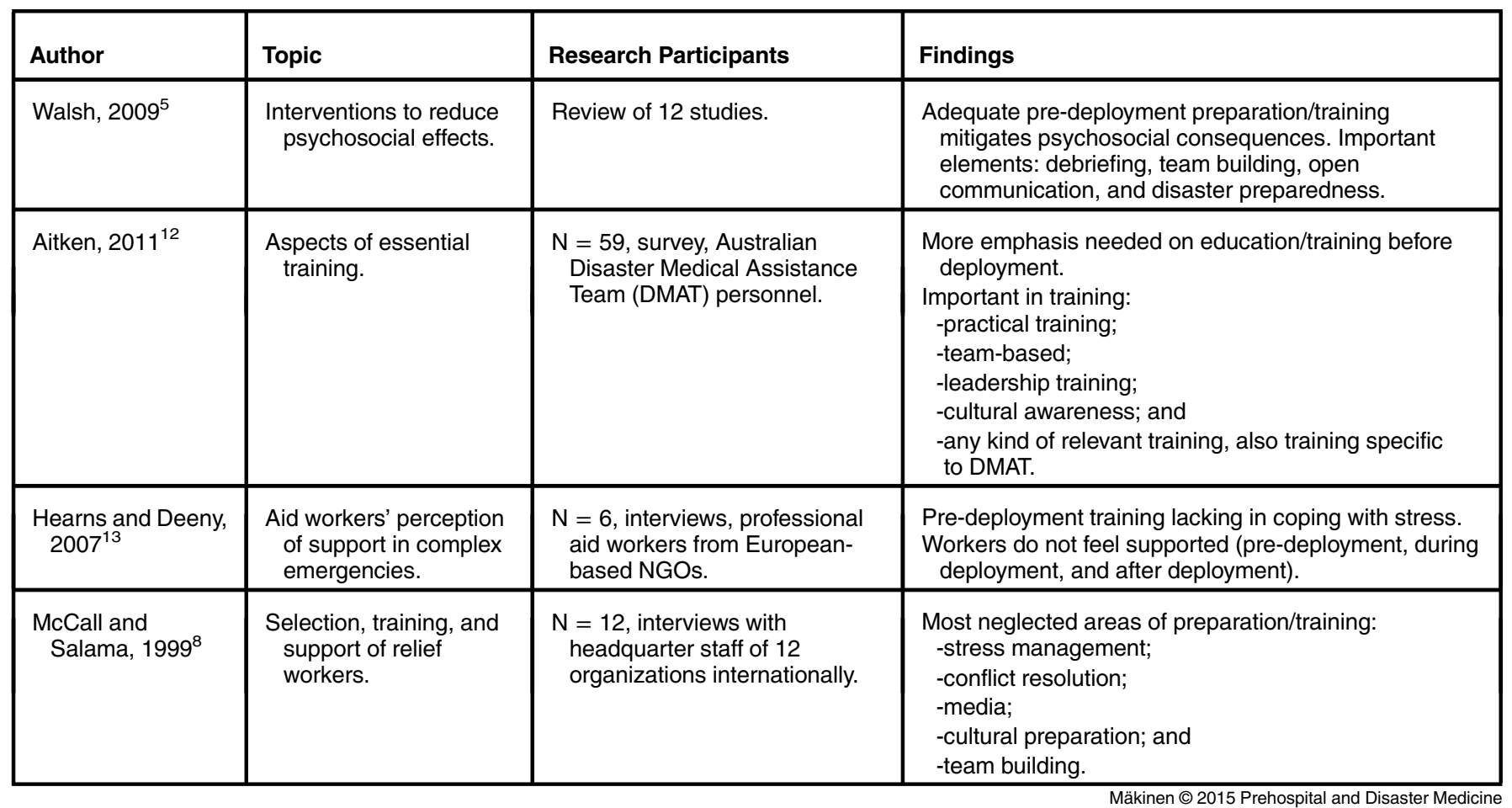

Table 1. Evidence Table Showing Range of Approaches to Preparation and Support of Humanitarian Aid Workers Abbreviations: DMAT, Disaster Medical Assistance Team; NGO, nongovernmental organization.

Mental well-being was chosen as the working concept in this study, as it encompasses a wider range of meanings than the perhaps more clinical concept of mental health. However, many elements pertain to both of these concepts: mental well-being is, in this study, defined along the lines of the World Health Organization's (Geneva, Switzerland) definition of Mental Health, of achieving one's potential, coping with normal life stresses, being able to work productively, and contributing to community. ${ }^{10}$ Additionally, mental well-being is seen as holistic, and while influenced by culture, includes elements such as a positive and adaptive outlook on life, feeling connected, and demonstrating a resourcefulness to cope. ${ }^{11}$

An overview of the relevant research evidence indicates a need to develop support and preparation for relief workers (Table 1)..$^{5,8,12,13}$ The studies examined varied in size, method, and scope of study. Included within the literary reviews were also some studies which did not involve disaster-relief personnel specifically. The elements in common to these studies relate to issues such as team working, stress management, conflict resolution, handling media, practical skills, and cultural preparation (Table 1). An earlier study of 12 leading aid organizations revealed that while it is known that relief workers are subject to psychological stress, psychosocial support and preventive mental health measures for deployed staff are underdeveloped. ${ }^{8}$ According to recent comprehensive research, less than one-third of the 20 participating international organizations evaluated their staff care practice, and none had conducted publicly available research on the topic. ${ }^{14}$ Similarly to psychological support advocated for mental health providers in complex emergencies, ${ }^{15}$ mental well-being support needs to be advocated for all humanitarian workers to mitigate negative mental health outcomes. A recent review of existing literature on the mental health consequences of relief work concluded that the high rate of occupational stress and trauma reported indicates a need for research in the specific pre-deployment training and support appropriate for preparing and sustaining workers. ${ }^{4}$ Organizations have become more aware of the need for the provision of adequate pre-deployment preparation, and various approaches and resources have been developed to mitigate negative effects on workers' mental health. ${ }^{14,16}$ However, the appropriateness of that preparation to support mental well-being as perceived by the personnel has not yet been researched sufficiently, and is not always known at the organizational level. ${ }^{7}$ While a limited amount can be done to change external stressors common to disaster-related work, potential exists for improved organizational support through pre-deployment preparation of personnel.

The organization chosen for this case study is a relatively young and small international rapid-response, emergency-relief unit, which offers medical aid, light search and rescue, fire suppression, trauma counseling, disaster childcare, and logistical support. In addition to its willingness to participate in this case series, the organization was chosen for its practical method and unique staged process of pre-deployment preparation.

The aim of this case study was to gain insight into the perceptions of deployed emergency-relief personnel of the chosen organization in regard to the pre-deployment preparation they had received, and its appropriateness in supporting the volunteers' mental well-being on the field and on return. The study proposed to identify elements of support which were considered important and experienced as helpful, as well as those lacking in the preparation. This case series will inform the wider disaster health care community, albeit in a limited and non-generalizable way, of the elements considered important by the personnel in supporting mental well-being, as well as the role that pre-deployment preparation plays in the same. It will contribute to the development of suitable 
training and preparation practices in order to mitigate the negative psychosocial effects of disaster-relief work. ${ }^{7}$ The research questions posed were: What are the elements in pre-deployment preparation that support mental well-being? What elements were lacking and would be useful?

\section{Methods}

As a live deployment situation would make it very difficult to conduct in-depth interviews, a post-deployment approach was adopted, allowing multiple deployment experiences of participants to be charted. To aid in recall of the organizational preparation, the content topics of the introductory course were summarized for the participants during the interview. A qualitative, hermeneutic phenomenological approach was chosen to understand the lived experience of the subjects, ${ }^{17}$ in order to "gain insightful descriptions of the way we experience the world pre-reflectively." ${ }^{18}$ A case series approach was chosen as it enabled a more detailed examination of the significance of one specific pre-deployment preparation program. This approach was also considered suitable for exploring the depth of participants' experience, as shown through another study describing the psychological trauma experienced by a disaster-relief worker. ${ }^{19}$

Participants were recruited through a contact person in the organization from a pool of candidates fulfilling the pre-requisites of having undergone the required stages of pre-deployment preparation and having deployed with the organization at least once. Skype (Microsoft Corporation; Redmond, Washington USA) interviewing was chosen as a suitable method of obtaining data, due to its cost-effectiveness in reaching participants internationally. ${ }^{20}$ Data were obtained through the interviews with consenting volunteers of the organization. The interviews were audio recorded (with Amolto Call Recorder from Skype) and transcribed. Content analysis was used for the analysis of the transcripts.

\section{Participant Demographics}

Participants included both genders, with several nationalities and training-base locations of the organization represented. The number of deployments and locations of deployments varied. While the organization does not require formal qualifications, its members include practicing health professionals and other professionals. Further demographic information is withheld to retain anonymity also within the organization.

\section{The Interview}

A pilot interview (not included in the research data) was conducted with a deployed staff member in order to provide feedback on the suitability of the interview questions and to refine interviewing skills. The interviews were conducted through Skype, at a time agreed to by both the researcher and the participant. The interviews lasted about one hour each and were conducted in English. A thematic, semi-structured interview enabled the participants to talk freely, while enabling the preparation of interview themes beforehand. ${ }^{21}$

While the theoretical background from previous research (Table 1) was utilized in the interview themes in order to elicit a wide approach by the participants to the research question, the emerging themes were derived from the data itself. The interview themes covered the following sections:

1. Elements considered important in pre-deployment preparation for supporting mental well-being during and after deployment;
2. Elements in the participants' pre-deployment preparation which supported mental well-being during and after deployment; and

3. Elements experienced as lacking in the participants' pre-deployment preparation for supporting their mental well-being during and after deployment.

Ethical Aspects

Participant identity was protected by removing all identifying information, such as gender, nationality, and occupation, where it could identify the person also within the organization. In addition, any other comments or expressions which may identify the participant were removed from the data. Any identifying information was also removed from direct quotes. Participants were given an opportunity to be referred to staff support of the organization to address any issues re-surfacing during the interview. The study was approved by the Faculty Ethics Committee at the University of South Wales (United Kingdom), as well as endorsed by the international council of the organization in question. Participants received a Letter of Information prior to signing a consent form for the interview, its audio recording, and eventual publication (herein).

\section{Data Analysis}

Interview transcripts were read through several times, during which broad themes were identified. Phrases relevant to this study were identified and highlighted. The data provided were classified and categorized according to emerging themes and patterns using content analysis. This is a concise, yet broad, description of the phenomenon achieved in a category form. ${ }^{22}$ The data were processed in a similar fashion to a study by Ranse and Arbon, ${ }^{23}$ adapted from van Manen, ${ }^{18}$ for the analysis of the text to deduce categories and verify the process outlined in Table 3. Lauri and Kyngäs recommend a data-based approach when existing research is limited or fragmented. ${ }^{22}$ The general process identifying broad themes and sub-themes as outlined in Elo and Kyngäs ${ }^{22}$ is exemplified in Figure 1. An external reader provided additional credibility.

\section{Results}

The results regarding the appropriateness of the pre-deployment preparation in supporting mental well-being were divided into two sections: elements which were considered helpful or important and elements found to be insufficient.

\section{Elements Considered Helpful or Important in Pre-deployment} Preparation for Supporting Mental Well-being

Participants' responses were grouped under the following seven themes that were identified from the data: (1) realistic expectations, (2) team building and support, (3) self-awareness and self-care, (4) post-deployment support, (5) practical skills and creative solutions, (6) shared values and beliefs, and (7) safety and security. Sub-themes were identified where relevant (Table 2). Several issues were noted specifically as meaningful in the pre-deployment preparation for the "returning home" phase, noted under the relevant themes (self-awareness and self-care and post-deployment support).

Realistic Expectations-Practical exercises and simulations tied in with the theoretical learning, as well as sharing of stories and personal experiences by staff and trainers, enabled the forming of a realistic picture of what can be expected on the deployment and on return (Example 1). Honesty about security, living conditions, and 


\begin{tabular}{|l|}
\hline Realistic Expectations \\
\hline -sharing of stories and experiences \\
-honesty about security, living conditions, and stress \\
-preparation for the unknown/unexpected \\
-scenarios/practical learning tied into theoretical learning \\
-communication with family/friends of risks in deployment \\
\hline Team Building and Support \\
\hline -support of the team during and after deployment \\
-team building prior to deployment \\
-leadership \\
-communication \\
\hline Self-awareness and Self-care \\
\hline -awareness of experiences possible post-deployment \\
-having support systems in place \\
-knowing yourself/team \\
-counseling teaching, personality tests \\
-team leaders getting to know you, feedback \\
-recognizing lingering issues after deployment \\
-assessing coping mechanisms prior to/after deployment \\
\hline Post-deployment Support \\
\hline -support network set up previous to deployment \\
-team and individual debriefing (immediate and later) \\
-remaining connected to team after deployment \\
-preparation for time of rest and recuperation \\
\hline Practical Skills and Creative Solutions \\
\hline -broad set of basic skills for further development \\
-scenarios where skills practiced \\
-preparation for the "unknown" \\
-ability to use resources available \\
\hline -collective purpose \\
\hline Shared Values and Beliefs \\
\hline
\end{tabular}

Mäkinen () 2015 Prehospital and Disaster Medicine

Table 2. Elements Considered Important in Supporting Mental Well-being in Pre-deployment Preparation (Themes and Subthemes)

the stress experienced in the deployment was identified as helpful (Example 2).

I think what helped me a lot is the personal stories of the others, just to give a picture of what it could be like, to give the participants an idea what they could expect, so you can already think about oh, how would I cope with this or that situation... (Example 1).

...understanding that the conditions are going to be very bare...that my diet will be consisting of MREs [Meals Ready to Eat], nuts and beef jerky...that I will most likely be tenting, so pretty much the introductory course prepared us to expect the worst, come expecting that... (Example 2).

While the preparation for developing an awareness about the unknown and unexpected situations that can take place on deployment was interpreted as being very beneficial, it was recognized that no amount of training or preparation can prepare for the experiences in the field completely. Participants perceived that while previous life experiences contribute in a more significant manner to supporting mental well-being: "the life experience that you bring that's basically the foundation, that's what you bring in;" they acknowledged the role of the preparation in addressing specific things outside the scope of normal life (Example 3).

Of course, all my previous experiences in life, that's what I am already carrying for...years and...the course is two weeks, but I really see the added value of the...course, about talking and experiencing how to cope with the specific things...I think all my previous experience in normal, general life are also more general experiences what you are bringing with, but the things we are talking about during the...course is so specific for deployments, and a deployment was also a new experience for me, so that was not that I could put out knowledge from previous life because I had never experienced a deployment (Example 3).

Team Building and Support-In the number and intensity of responses, the team was identified as one of the most important contributors to mental well-being during and after deployment, and it was interpreted as having provided safety and security, as well as reduced stress. Team building prior to deployment, during all phases of the preparation, was perceived to build trust, safety, unity, and acceptance (Example 4). The intensity of living and working together, often under stressful conditions, during the introductory course and in staffing the same course, came across as key factors in achieving this. Being acquainted with the characteristics, capabilities, working styles, and strengths and weaknesses of other team members prior to deployment was considered valuable.

I think that really helped me or supported me. I knew some people I can talk to and trust, they would listen to me; I can be very honest, I knew they were there for me... And that was just because of the time we had before where I, even during the course, I had some chats maybe with them and I felt very safe with them...And just also to have maybe a common story, like you know if you're stressed or if it's challenging, it's easier maybe to do something fun or maybe also to know how people are, like how they react or how you can communicate... (Example 4).

Team leadership was also portrayed as important in providing support before, during, and after deployment in the form of being in contact prior to deployment, being available and present during the deployment, and following up after deployment. Getting to know the leaders and their leadership styles before deployment, as well as the leaders getting to know the team members and giving feedback, was seen as positive. Participants noted that remaining in touch with the team and leaders in various ways (Skype, phone, or visiting) after the deployment continued to provide significant support.

In addition to team cohesion, the pre-deployment preparation was identified as assisting in team communication. This included constructive conflict resolution, the importance of good communication, and being aware of the ease of miscommunication, especially being an international and inter-cultural organization.

While not an objective of this study, the positive influence of the distinct phases of preparation (introductory course followed by 


\begin{tabular}{|l|l|}
\hline Step 1 & $\begin{array}{l}\text { Familiarization with data (reading through several } \\
\text { times) }\end{array}$ \\
\hline Step 2 & Identifying broad themes \\
\hline Step 3 & Division to "during deployment" and "after deployment" \\
\hline Step 4 & $\begin{array}{l}\text { Copying and pasting relevant phrases onto a separate } \\
\text { document }\end{array}$ \\
\hline Step 5 & $\begin{array}{l}\text { Highlighting of relevant phrases in transcripts by } \\
\text { external reader }\end{array}$ \\
\hline Step 6 & Checking of phrases found by external reader \\
\hline Step 7 & Grouping phrases into themes and subthemes \\
\hline Step 8 & Revision of themes; Rechecking of data \\
\hline
\end{tabular}

Table 3. Process of Data-based Content Analysis Adapted from Ranse and Arbon ${ }^{23}$

staffing the same) became evident. Participants expressed that "there were aspects that helped me more the second time," referring to the staffing of an introductory course and "I think that was more the staffing than the introduction," where another participant experienced a stronger bonding to the others.

Self-awareness and Self-care-A salient point identified was the benefit of the scenarios and simulations during the predeployment preparation in getting to know personal strengths and weaknesses, as well as limits in the types of things that one may face on deployment (Example 5). The personality tests and counseling teachings were interpreted as being helpful in getting to know oneself. Recognizing one's reactions to challenging situations and becoming aware of personal coping mechanisms to deal with stress were some of the issues identified as supporting participants in preparation for the deployment. This was also recognized as helpful in the team context.

...especially all the kinds of scenarios, I think that really gave more an understanding of...it is stressful...they built up the tension in the different scenarios...during the scenarios it was really that I got an idea or understanding of how to work under stress and how to work under all kinds of inputs...that was for me really supporting (Example 5).

Participants indicated that self-care needs to begin before the deployment. The availability of designated team members during deployment for mental health support, as well as the team leaders for questions and concerns, was made known already in the introductory course and was identified as supportive.

In preparation for returning home from deployment, hearing the personal experiences and stories, even struggles, of staff and leaders brought awareness to the range of personal experiences that can take place. This aided in recognizing any issues that they may be dealing with after deployment (Example 6).

I think it was also good in the training to hear some stories from some staff, like just what they experienced...in another deployment... [when they] came home and...how it was for them...to be aware what could happen or what reaction could be. And also to hear that it's kind of normal to maybe react differently to what I am used to...I think that some stories out of their own experience, I think that was helpful (Example 6).

Several issues were portrayed in the context of preparation for post-deployment. Gauging personal capacity for return to normal life in regard to workplace and employer awareness, as well as family and spouse considerations were identified. Recognizing lingering issues after deployment and assessing personal coping mechanisms prior to or after deployment were identified as contributing to self-care.

Post-deployment Support-The need for support networks to be in place already before the deployment was identified. This included emotional/social, spiritual, as well as financial support. While volunteer were encouraged to set up personal support networks in the preparation phase, it was up to them to actually do it (note: areas of support included financial, as the deployed members are volunteers, responsible for either paying their way or raising financial support). All participants indicated personally having sufficient post-deployment support networks. Emotional and social support networks consisted of friends and family and professional workers, such as psychologists or therapists (Example 7). The value of spiritual and prayer support to the participants was identified as providing encouragement both during and after deployment. This came from within the team and from individuals' support networks, such as a sending organization or church, family, and close ones.

...I did build up that social network ahead of time, I was really ready to go with my network surrounding me, and when I came back I already had asked people will you just listen to me, so I have that all set up... And my psychologist...is very good...gives me a lot of practical tips on how to deal with things... (Example 7).

Debriefing with the team immediately after the deployment, and also at a later stage individually, was interpreted as being very supportive, as was remaining in touch with team members in an unofficial context. Follow-up by the team leader was identified as meaningful.

Specifically pertaining to preparation for the after-deployment phase, remaining connected to the team after deployment and preparation beforehand for rest and recuperation were identified as significant.

Practical Skills and Creative Solutions-Participants identified learning a broad range of practical skills and possessing a suitable skill-set as being supportive on the deployment. They recognized that due to such a short preparation, further extra-curricular training may be required. The "hands-on" approach in the training and preparation was identified as significant (Example 8). What to pack on deployment (note: volunteers carry 10 days of food supply each) and making do with available resources and problem solving during the scenarios were identified as useful, and learning radio communication was considered particularly helpful in deployment. The scenarios and simulations, done in a team context, were interpreted as valuable (Example 9). Receiving feedback from the scenarios was identified as helping to critically develop personal skills and awareness.

I really enjoyed how broad it was...I really enjoyed the search and rescue and all kinds of things, and...how the different 


\begin{tabular}{|c|c|c|}
\hline Example Phrases & Sub-theme & Theme \\
\hline $\begin{array}{l}\text { "...the team plays a very significant role in supporting you on } \\
\text { deployment" }\end{array}$ & \multirow{3}{*}{$\begin{array}{l}=>\text { support of the } \\
\text { team during and after } \\
\text { deployment }\end{array}$} & \multirow{11}{*}{$\begin{array}{l}\text { Team } \\
\text { Building and } \\
\text { Support }\end{array}$} \\
\hline $\begin{array}{l}\text { "Knowing that I have that cushion, I can trust them...I have a } \\
\text { shoulder to cry on if I need to, is definitely a good thing." }\end{array}$ & & \\
\hline $\begin{array}{l}\text { "...just to stay in touch with our team, either with Skype or } \\
\text { visiting each other, it was really nice, because then I felt I don't } \\
\text { need...to explain like what we experienced" }\end{array}$ & & \\
\hline $\begin{array}{l}\text { "... if you know the people around you, I think that serves your } \\
\text { mental health a lot, because you know who you work with and } \\
\text { you trust them, it just builds a lot of trust" }\end{array}$ & \multirow{2}{*}{$\begin{array}{l}=>\text { team building } \\
\text { prior to deployment } \\
\text { (trust, safety, unity, } \\
\text { and mutual respect) }\end{array}$} & \\
\hline $\begin{array}{l}\text { "...to know I go out with friends or with people I trust and know, } \\
\text { I think can help a lot just to cope with a lot of situations" }\end{array}$ & & \\
\hline $\begin{array}{l}\text { "I find it very helpful that... leaders said that if there is } \\
\text { something, come and speak and really share what is on your } \\
\text { heart and how you are doing, and so I felt...I could do that." }\end{array}$ & \multirow{3}{*}{$\begin{array}{l}\text { => team leadership } \\
\text { (support of leaders } \\
\text { before/during/after } \\
\text { deployment, knowing } \\
\text { leaders beforehand, } \\
\text { leadership style, and } \\
\text { trust) }\end{array}$} & \\
\hline $\begin{array}{l}\text { "...for me, leadership is really that can I trust somebody that is } \\
\text { he's having the right heart and wanting the right thing for the } \\
\text { team and the people we are serving" }\end{array}$ & & \\
\hline $\begin{array}{l}\text { "...leading the deployment and he was really consciously going } \\
\text { after every team member... and that was really meaningful I } \\
\text { think." }\end{array}$ & & \\
\hline $\begin{array}{l}\text { "... really showed that how important good communication is } \\
\text { and confronting in a good way. And how it makes teams } \\
\text { stronger..." }\end{array}$ & \multirow{3}{*}{$\begin{array}{l}=>\text { team } \\
\text { communication } \\
\text { (constructive } \\
\text { conflict/tension } \\
\text { resolution, } \\
\text { importance of good } \\
\text { communication, } \\
\text { awareness of ease of } \\
\text { miscommunication) }\end{array}$} & \\
\hline $\begin{array}{l}\text { "...communication is always, always a thing that we can } \\
\text { improve and it's always also the point of getting frustrations, } \\
\text { getting different ideas or interpretations, especially... when we } \\
\text { are international, we have different cultures..." }\end{array}$ & & \\
\hline $\begin{array}{l}\text { "... communication was something that was stressed out really } \\
\text { well, that if I were to go out...I needed a line between me and } \\
\text { my leaders, like for example (if) we were out in the } \\
\text { communities..." }\end{array}$ & & \\
\hline
\end{tabular}

Figure 1. The Process of Identifying Sub-themes and Themes.

people could fit in the different areas of expertise...I think in the scenarios, I learned the most compared to lectures in the classroom....and it's really "hands on" -we really "do" search and rescue, we do medical, whatever, and radio communications and it's really practical, and I really enjoy that (Example 8).

The disaster scenarios were surreal...it was like really, really being there; they tried their best to simulate what it is like to be in a disaster; amazing, having those scenarios and having them often, it was good, it kept us on our toes and prepared us to what it is like there (Example 9).

Shared Values and Beliefs-An important area contributing to participants' mental well-being was the spiritual dimension of support, as mentioned also within the area of post-deployment support. Possessing similar values and world-views, and having similar previous experiences with the umbrella organization 
(note: prerequisite training for participating in the introductory course), was interpreted as helpful and unifying (Example 10).

...for the pre-deployment phase, I think what also really is a good value, is the whole [umbrella organization] value...the background we have...we all have the same heart and same compassion, also that you feel safe in a group although you know the people just for a few days and you connect to them and it is good...everybody helps with the same heart, with the same compassion, with the same idea (Example 10).

Personal faith, clarity of purpose personally and collectively, was interpreted as meaningful. Prayer support within the team and from sending organizations or groups was identified as very important both during and after deployment (Example 11).

I think especially the spiritual aspect... because I think like the other [nongovernmental organizations] NGOs are quite well with preparing all kinds of things, but it is all more about like "what I can do to change the situation" and in [the organization], it's more...of course "what can I do, what can we do" like medically and search and rescue, and so on, but it is still this taking God with us... in our hearts and minds, to know it's not all about us and what we can do. I think it's just a different mindset (Example 11).

Safety and Security — Safety and security preparation encompassed personal and team safety, as well as field awareness and preparation for potential incidents on deployment, such as hostage situations and land-mines. Safety and security preparation was interpreted as important and supportive in mental well-being (Example 12).

That was, I think, adequate in my own course...to have it repeated, that really helped me because it's just refreshing it... I think it is sufficient but I am not sure if that gives you all the tools that you need if it actually happens (Example 12).

\section{Elements Considered Insufficient in Pre-deployment Preparation for Supporting Mental Well-being}

The majority of the participants' comments were identified as positive regarding the support they had experienced for mental well-being stemming from the preparation of the organization. However, some perceptions were identified as more negative, where preparation had supported only minimally. Several areas for improvement and weaknesses in support were identified.

The safety and security theme was identified from the interviews as the major area where the sense of importance placed on it by participants did not match the level of preparation they felt they had received, especially in light of the growing risk of violence to humanitarian workers on the field. The majority indicated that they had not felt that the preparation had prepared them for the deployment sufficiently (Example 13). Several suggested that additional training would be useful, especially in conjunction with scenarios involving security issues. Extra-curricular training was identified as an option for further preparation in this area. Body retrieval, while not a pre-planned activity for one of the deployments, identified concerns about the team's preparedness and protection required.

...I think it could be much more extended... make people aware what included personal safety and team safety, what are those things to be aware of, behaving, because some of the situations are quite tense and it is not what I am used to, and so sometimes I think I don't even realize maybe this could be very dangerous...I think security is something we talk a bit about, but not much; but I think that can be a huge stress factor, and I think we could do more there (Example 13).

Current focus on the medical training was interpreted as shadowing other areas, such as security and disaster childcare, which are also among the scope of the organization's work. Additionally, the emphasis on the first response was identified as skewed in relation to the need experienced on the field: the need for more preparation for wound care (Example 14).

...we had all kinds of medical teachings, but the wound care, which is the major thing, was not much mentioned...to have more the practical, or practice, how do I stitch a wound, what options do I have in such a setting to clean a wound, such things I think...we learn a lot about emergency medical, like someone has got cut off an arm, what do I do, but that's usually or not what we experienced in the field: old big wounds, a week old, not cleaned, and really infected... (Example 14).

The area of support networks and post-deployment support was identified as important but lacking. Returning home from deployment was interpreted as an area needing "gearing up on;" in theory, the support networks need to be there for each volunteer, but this needs to translate into practice. Organization-level involvement to ensure sufficient support networks were set up before deployment was identified as a possible intervention. Setting up these networks in time was identified as key for easing the chaotic phase immediately before the deployment. While the need for post-deployment support was emphasized, the individuality of persons and responses was also identified: "everyone is coping in a different way." Preparing the people back at home for the volunteers' return was brought up, especially in regard for superiors and leaders to gauge how the volunteer is doing and readiness to return to work.

Another salient area was communication: good communication, especially within the team, was interpreted as an area where there is always room to improve, with the ability to resolve conflict, openness about personal struggles, as well as a need for more inter-cultural understanding within the team identified. The need for more time for team building during the staffing phase of the preparation was identified, with the recognition of the lack of time for it once deployed. While delegation of communication with the media during the deployment was interpreted as being handled well, the need for more briefing on what and how to share after the deployment was identified. Unclarity in roles assigned by leadership was interpreted as having been experienced as somewhat confusing.

In general, the value of personal stories in the preparation was highlighted, and as the organization has had more people deployed, this was identified as less of an issue. A practical approach with stories and coming from personal experience of the trainer was voiced as important in making the Disaster Psychology topic more relevant.

The need for preparation for stress management, and generally prevention in the area of mental well-being, was identified, as well as the area of physical health to cope with the demands of the deployment. A yearly refresher, for example through an online module, was suggested to improve preparation and prevention in view of mental well-being issues. 


\section{Discussion}

The pre-deployment preparation was appropriate for supporting mental well-being in these participants. The issues identified as important in supporting mental well-being generally were also the elements where support was experienced. The elements of support considered important for supporting mental well-being raised in this research (Table 2) are in line with previous research (Table 1). The major difference is that the results of this study showed a generally positive outlook on the support received for mental wellbeing by the participants, contrary to previously mentioned studies where a significant lack in support has been expressed (Table 1). The positive results may be due to several reasons:

1. The small size of the organization: trainers are often leaders on deployments and get to know prospective volunteers at an early stage before deployment.

2. The process of student-trainee-member where, in addition to participating successfully in the initial introductory course, prospective volunteers are required to staff one, and only after their first deployment will they be accepted as full members. This process may thin out unsuitable candidates early on, as well as provide a gradual "growing into" the role of emergency response personnel, where the volunteers are able to recognize personal support needs and ensure sufficient support networks.

3. Similar previous training undertaken as a prerequisite for joining the organizational training and an emphasis on "team" mentality, which has been shown to be a major factor in mental well-being and support.

4. Personal faith of the volunteers and a strong organizational ethos resulting from shared faith-based values.

5. The organization having, in recent years, emphasized the importance of member care and support, while continuously developing their preparation program in order to provide adequate support for their volunteers on the field.

6. A selection of participants who happened to be more inclined to contribute positively, possibly due to their personal experiences of having received support.

Other possible explanations for the positive interpretations of this study may be found outside of the preparation itself, from factors which have been found to contribute to mental well-being in disaster relief. Satisfaction from helping and empowering people, a strong desire to respond, dedication, optimism, altruism, finding meaning in the work, receiving support, and recognition have been identified as empowering factors. $5,24,25$ Campbell et $\mathrm{al}^{26}$ found that providing unpaid volunteer service in shortterm missions may contribute to enhanced mental well-being.

"Shared values and beliefs," identified by participants in this case study as important and supportive, has not emerged as a salient theme in previous research as such, but elements of it may be identifiable in the above-mentioned research. While these positively contributing factors were outside the scope of this study, they are an interesting aspect for further research. "Shared values and beliefs," having come up clearly as one the supporting elements of mental well-being, can be understood through the organizational and participants' personal values being in agreement. It has been recognized that a discrepancy between personal and organizational ethics and mandate can be a cause of tension in humanitarian work, ${ }^{27}$ implying that a strong ethos may contribute to staff support, as was found in this study.
The preparation for developing an awareness about the unknown and unexpected situations that can take place on deployment seems to be beneficial. However, it is important to realize that no amount of training or preparation can prepare for the experiences in the field completely. While this recognition does reiterate the reality of disaster-relief work, it does not provide an excuse for lack of provision of organizational preparation. An awareness of the "unexpected conditions that can be expected" is a significant contributor to mental well-being.

Perceived support of the team, and team building prior to deployment, seem to be very important in this case. In many disaster response organizations, however, teams are compiled immediately prior to deployment and do not benefit from team building. Working in the complexity of a multicultural and multidisciplinary team can be a stress factor in itself. The need for teams to train together pre-deployment has been expressed previously $^{12}$ and reflects the importance of social support expressed by humanitarian workers. ${ }^{28}$

Elements identified as lacking in the pre-deployment preparation, such as communication, support networks, safety and security, stress management, and preventive mental well-being strategies, are found similarly to be so in previous research (Table 1). It is understandable that communication within the team becomes even more meaningful due to the demanding nature of these assignments. An area of improvement in staff preparation for relief organizations on the whole would be in team building and conflict resolution skills, as they have been found lacking in previous research (Table 1). These would likely directly contribute to improved communication within the team, as expressed by the participants of this study.

Support networks are an area to improve in this case, although all participants indicated they have adequate support networks themselves. This implies an awareness of, and concern for, the team and organization as a whole. As some of the deployed volunteers are potential trainers for future personnel, the ability to identify areas of weakness and strength in the preparation are key to future developments in it.

Team and individual debriefing was expressed as an important part of post-deployment support, and has been found effective in reducing negative psychological symptoms. ${ }^{29}$ Improving and continuing two-way communication, even after re-entry, between the worker and the organization is valuable in supporting the worker. ${ }^{13}$

Security and safety is an area brought up as lacking in the preparation. This does not come as a surprise, as an extensive evaluation study in 2001 on 53 organizations' practices in their pre-deployment preparation of international relief workers found that about half of the organizations did not provide any security training or resources. ${ }^{30}$ Considering the increase in security incidents towards relief workers over the last decade, hopefully the percentage of organizations providing security preparation has increased since that time. It is important for organizations to provide sufficient preparation to their personnel, not only for the event of an incident, but also for the aspect of mental well-being; as expressed in the interview, not feeling prepared can be experienced as a major stress factor.

\section{Further Research}

Strong research evidence already exists on the negative mental health effects of disaster-relief work on personnel. With growing awareness of organizations of the need for the provision of 
adequate pre-deployment preparation for their staff, further research is needed on the role pre-deployment preparation can play in providing appropriate mental well-being support, and thus, mitigating these negative outcomes.

It may be worthwhile for the organization in question to consider conducting a quantitative follow-up survey for improved representation. As the organizational preparation is updated and improved continuously, the currency of the preparation of the participants is a key consideration. A follow-up survey in several years may assist in comparing results and defining achievements. As a practical recommendation, other organizations interested in developing their pre-deployment preparation should aim to elicit continual feedback from returning field personnel, as an understanding of their perceptions of the support is key to developing the suitability of preparation programs.

\section{Bias}

The results showing a generally positive experience of support, the researcher attempted to minimize any personal positive bias by judiciously seeking out any comment and phrases which would provide evidence for a lack of perceived support. The use of the reader was beneficial in minimizing bias and added to the reliability of the results.

While the main researcher (TM) is not involved personally in this organization, she has ties to the affiliated organization. This may subconsciously affect bias; however, as the very aim of this research has been to reveal "lacks" and shortcomings in the current preparation program in order to improve future preparation of volunteers, this would be minimal. A further manner of reducing any bias is the decision to conduct this research anonymously in regard to the organization, so the results would be neither shining any positive nor negative light on the organization itself.

\section{Limitations}

Despite the fact that each interview theme related to the mental well-being of the participant and the quality and quantity support they felt they had received, the participants often responded in a more generalized way. It was noted that instead of answering "How well...supported?" the participants, in essence, often

\section{References}

1. Inter-Agency Standing Committee. IASC Guidelines on Mental Health and Psychosocial Support in Emergency Settings. http://www.who.int/mental_health/ emergencies/guidelines_iasc_mental_health_psychosocial_june_2007.pdf. Published 2007. Accessed May 3, 2014.

2. Antares Foundation. Managing Stress in Humanitarian Workers: Guidelines for Good Practice. http://www.antaresfoundation.org/download/managing_stress_in humanitarian_aid_workers_guidelines_for_good_practice.pdf. Published 2012. Accessed May 3, 2014

3. Lopes Cardozo B, Gotway Crawford C, Eriksson C, et al. Psychological distress, depression, anxiety, and burnout among international humanitarian aid workers: a longitudinal Study. PLoS One. 2012;7(9).

4. Connorton E, Perry MJ, Hemenway D, Miller M. Humanitarian relief workers and trauma-related mental illness. Epidemiol Rev. 2012;34(1):145-155.

5. Walsh D. Interventions to reduce psychosocial disturbance following humanitarian relief efforts involving natural disasters: an integrative review. Int J Nurs Pract. 2009; 15(4):231-240

6. Fullerton CS, Ursano RJ, Wang L. Acute stress disorder, posttraumatic stress disorder, and depression in disaster or rescue workers. Am J Psychiatry. 2004;161(8):1370-1376.

7. McFarlane C. Risks associated with the psychological adjustment of humanitarian aid workers. The Australasian Journal of Disaster and Trauma Studies. 2004:1.

8. McCall M, Salama P. Selection, training, and support of relief workers: an occupational health issue. BMJ. 1999;318(7176):113-116.

9. The Sphere Project: Humanitarian Charter and Minimum Standards in Humanitarian Response. 3rd ed. Rugby, England: The Sphere Project; 2011. answered the question "What...supported?" While this nevertheless describes their perception of issues pertaining to mental well-being support, it may be indicative of either the difficulty in quantifying such issues, or a lack of clarity in the interview themes attributable to the inexperience of the researcher.

On several occasions, the interview was interrupted by Internet connection problems, and once the final minutes of the interview were conducted by phone. Due to the relaxed nature of the interviews, these disruptions did not disturb the interview significantly, and audio recording was not interrupted.

As a case series, the results cannot be generalized. The practical application of the results are limited to illuminating aspects of the volunteer preparation of the organization in question to further develop their preparation program. While a limited sample, even within the organization itself, the results are nevertheless consistent with elements identified in previous research as important for mental well-being support.

\section{Conclusion}

Overall, the participants' perceptions of the appropriateness of their pre-deployment preparation for supporting their mental well-being during and after deployment were positive. Many elements identified as important for mental well-being were also expressed as those where support was experienced. While the results of this study cannot be generalized, they do indicate the significance relief workers place on pre-deployment preparation for supporting mental wellbeing, not only during the deployment phase, but throughout the deployment cycle. The findings of this study highlight the need for, as well as the potential of, pre-deployment preparation in supporting the mental well-being of workers, as well as the importance of further personnel-focused research to evaluate organizational practices and support needs of disaster-relief personnel.

\section{Acknowledgement}

The authors would like to thank all the study participants. The main researcher (TM) would also like to thank Asssistant Professor Jamie Ranse for his encouragement, and the external reader for his valuable assistance.

10. World Health Organization. Mental health: a state of well-being. http://www.who int/features/factfiles/mental_health/en/. Accessed May 3, 2014.

11. Mental Health Association of NSW Web site. http://www.mentalhealth.asn.au/ home/item/110.html. Accessed October 3, 2013

12. Aitken P, Leggat PA, Robertson AG, Harley H, Speare R, Leclercq MG. Education and training of Australian Disaster Medical Assistance Team members: results of a national survey. Prehosp Disaster Med. 2011;26(1):41-48.

13. Hearns A, Deeny P. The value of support for aid workers in complex emergencies: a phenomenological study. Disaster Manag Response: DMR: An Official Publication Of The Emergency Nurses Association. 2007;5(2):28-35.

14. People In Aid/InterHealth. Approaches to Staff Care in International NGOs. www. peopleinaid.org/pool/files/pubs/approaches-to-staff-care-in-international-ngos.pdf. Published 2009. Accessed May 1, 2014.

15. Mollica RF, Lopes Cardozo B, Osofsky HJ, Raphael B, Ager A, Salama P. Mental health in complex emergencies. Lancet. 2004;364(9450):2058-2067.

16. International Federation of Red Cross Red Crescent. Managing stress in the field. http://www.ifrc.org/Global/Publications/Health/managing-stress-en.pdf. Published 2009. Accessed September 30, 2013.

17. Ilsley P, Kraseman K. Phenomenological Methodology. Metodix Web site. http://www. metodix.com/en/sisallys/01_menetelmat/02_metodiartikkelit/ilsley_phenomenological_ methodology/?tree:D=171120\%3B168595\&tree:selres=\&hrpDelimChar=\%3B\&parent Count=1. Accessed April 24, 2014.

18. van Manen M. Researching lived experience: human science for an action sensitive pedagogy. New York, USA: The State University of New York; 1990. 
19. Bilal MS, Rana MH, Rahim S, Ali S. Psychological trauma in a relief worker - a case report from earthquake-struck areas of north Pakistan. Prehosp Disaster Med. 2007;22 (5):458-461.

20. Cater J. Skype - a cost-effective method for qualitative research. Rehabilitation Counselors E Educators Journal. 2011;4(2):3.

21. Cohen D, Crabtree B. Qualitative Research Guidelines Project. Robert Wood Johnson Foundation Web site. http://www.qualres.org/HomeSemi-3629.html. Published July 2006. Accessed October 22, 2014.

22. Elo S, Kyngäs H. The qualitative content analysis process. J Adv Nurs. 2008;62(1): 107-115.

23. Ranse J, Arbon P. Graduate nurses' lived experience of in-hospital resuscitation: a hermeneutic phenomenological approach. Aust Crit Care. 2008;21(1):38-47.

24. Boldor N, Bar-Dayan Y, Rosenbloom T, Shemer J, Bar-Dayan Y. Optimism of health care workers during a disaster: a review of the literature. Emerg Health Threats J. 2012;5:7270.
25. Wang XL, Shi ZB, Ng SM, Wang B, Chan CL. Sustaining engagement through work in post-disaster relief and reconstruction. Qualitative Health Research. 2011;21(4):465-476.

26. Campbell C, Campbell D, Krier D, Kuehlthau R, Hilmes T, Stromberger M. Reduction in burnout may be a benefit for short-term medical mission volunteers. Ment Health Relig Cult. 2009;12(7):627-637.

27. Salama P. The psychological health of relief workers: some practical suggestions. Humanitarian Exchange Magazine. 1999;15.

28. Curling P, Simmons K. Stress and staff support strategies for international aid work. Intervention. 2010;8(2):93-105.

29. Lovell-Hawker D. "Guidelines for crisis and routine debriefing”. In: O’Donnell K, (ed). Doing Member Care Well. Pasadena, California USA: William Carey Library; 2002: 457-475.

30. Moresky RT, Eliades MJ, Bhimani MA, Bunney EB, VanRooyen MJ. Preparing international relief workers for health care in the field: an evaluation of organizational practices. Prehosp Disast Med. 2001;16(4):257-262. 